\title{
Modeling and verification of an excavator system - Axial Piston Pump, Kinematics and Load Sensing Flow Sharing Valve Block
}

\author{
Professor Dr.-Ing. Paolo Casoli, Dr.-Ing. Luca Riccò, Dr.-Ing. Dolcin Cesare* \\ Industrial Engineering Department, University of Parma (Italy) \\ *Walvoil S.p.A., Reggio Emilia (Italy) \\ E-mail:paolo.casoli@unipr.it
}

\begin{abstract}
This paper presents the results of a study focused on mathematical modeling of an excavator hydraulic system, composed by: the pump gray box model, the kinematics model and the valve white box model. The kinematics model has been realized using the planar mechanical library of AMESim ${ }^{\circledR}$ and is composed by the front excavation tool: the arm, the boom and the bucket. The valve section white box model has been validate with the comparison between the numerical and experimental result obtained during the laboratory tests. The excavator is equipped by a full flow sharing valve, that is very useful in this kind of machinery when during a digging cycle all the valve sections are used at the same time. In this paper the excavator mathematical model system will be composed by the pump, the kinematics and two valve sections. The new system will be validated with the comparison between the experimental results, obtained with two sections working at the same time, and the numerical results provided by the simulation. The experimental results will be obtained in two different working conditions: standard operation condition and flow saturation condition. This will show the mathematical model capability in the study of the interaction between all the system components and could be useful in the study of alternative control strategies towards energy efficient systems and new control system designs.
\end{abstract}

Keywords: Hydraulic Excavator, Load Sensing, Mathematical Model, Energy Saving.

\section{Introduction}

In the last years, the simulation of the kinematics and dynamics of multi-body systems is a topic of increasing importance in many industrial branches, due to its potential for providing insight into inherent effects governing the systems' behavior and for reducing manufacturing costs. Furthermore with the continuous petrol price rising the higher interest in energy saving is rising as well. Lots of researchers have been studying for years these topics.

Focusing on mobile machineries, one of the primary needs is that of consume the less energy possible to complete a working cycle, like a standard digging cycle[1]. In other words one of the principal target being that of achieving more efficient machinery. Due to this, one of the first goals for machinery producers is the energy saving toward the optimization of their products, the system components interaction, and also with the introduction of energy recovery systems. Study such a complex system (like an excavator) require time, know-how and lot of money. Thus mathematical models are always more used.

Typically, mobile machineries hydraulic system are composed by a variable displacement axial piston pump [2] and proportional directional valves [3]. The hydraulic system controls the kinematics movements, under user needs.

An excavator system is a very complex nonlinear plant, and for this reason a suitable mathematical model is needed as well as a good simulation tool.

Many qualities are required from mathematical models, including accuracy, predictability for the simulated 
system behaviors (stationary and transient) as well as low computation time.

The research reported in this paper describes the mathematical model, for a middle size excavator, that is under developing using AMESim $^{\circledR}$ modeling environment. The mathematical model has been developed to be as simple as possible while ensuring the original elements functions.

The following sections present the modeling of the pump, the flow sharing valve, the excavator kinematics and validated results of the pump model and valve models.

\section{Physical Modeling}

As already described in the introduction, the most important qualities required from a mathematical model of complex systems are: result accuracy, predictable of transient and stationary behaviors and at last but not least short calculation time.

Certainly in the individual components optimization study the first two characteristics play a predominant role, but in the complete system study, focused on the interaction between all the components, such as the pump, the valve and the kinematics a short computational time becomes very important.

Taking this into account, the mathematical model under development, has the skill of a short calculation time while maintaining a satisfactory accuracy and behaviors predictability.

The mathematical model is composed by: the pump graybox model, the kinematics model and the valve white box model.

\subsection{Pump Model}

The pump, mounted on the excavator, is a load sensing variable displacement axial piston pump [2] developed by Casappa ${ }^{\circledR}$ S.p.A. and belongs to the MVP series.

Its mathematical model has been validated, at steady state conditions, with the comparison between experimental and numerical results in previous work [4]. The validation of the model in transient condition is in progress. The pump mathematical model, depicted in fig.1, has been defined gray box because it is composed by the combination of white box model for its regulators, such as the pressure compensator (PC) and the flow compensator (FC), and the black box model of the pump's flow characteristic.

\subsection{Kinematics Model}

The kinematics model, shown in fig.2, is composed by the front excavation tool only: arm, boom and bucket.
The kinematics model is used to create realistic forces on the hydraulic actuators.

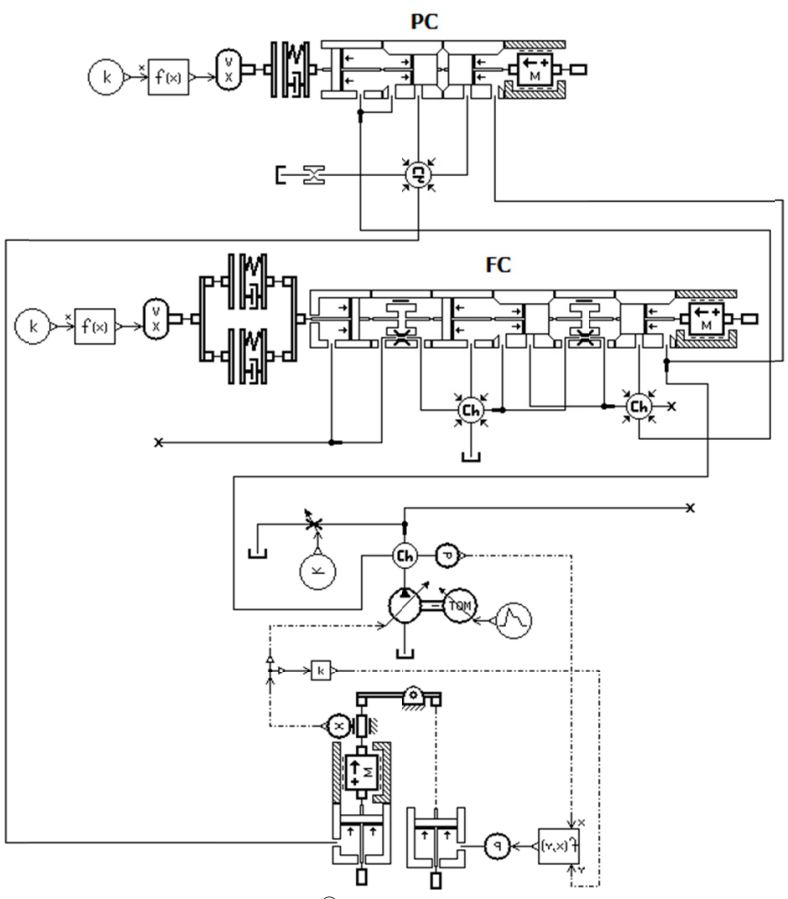

Figure 1: AMESim ${ }^{\circledR}$ Pump Mathematical Model

Considering the benefits of having the kinematic model integral with the hydraulic model, the linkage parameters were coupled to the hydraulic model using the Planar Mechanics library of AMESim $^{\circledR}$ [5]. This facilitates the understanding of dynamic loads on the hydraulic cylinder. The driving joint torques of the boom, arm and bucket are generated by the forces of the hydraulic ram actuators. The equations of motion can be derived by applying the Euler-Lagrange equations to a Lagrangian energy function. The revolute pairs have been modeled as Lagrange multipliers and are calculated from the Baumgarte stabilization method applied to the constraint equations [6]. The model is not yet set to simulate the forces acting on the bucket during the interaction with the soil [7].

\subsection{Valve Section Model}

The valve section is a full flow sharing valve by Walvoil $^{\circledR}$ S.p.a. and belongs to the DPX series.

Its mathematical model has been validated in [8], considering only one section working, with the comparison between the simulation and experimental results obtained during laboratory tests.

In a mobile machinery, such an excavator under study, the use of this kind of valve is very useful because during a standard digging cycle [1] are almost used all the valve sections at the same time. When this situation occur, the pump could work in flow saturation 
condition, i.e. the pump flow is less than the flow required by the valve block.

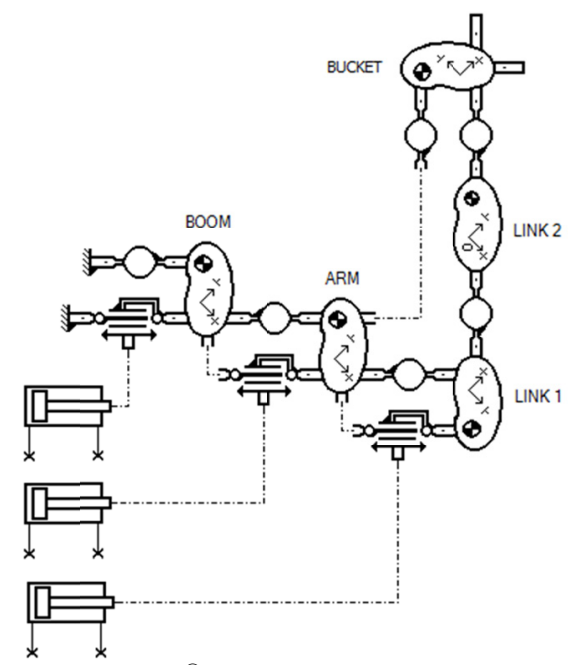

Figure 2: AMESim ${ }^{\circledR}$ Kinematics Mathematical Model

If this situation occur, the operator can lose the direct control on the moving parts, that could be very dangerous, but with this kind of valve the operator still maintains the control on the parts movements losing the control on their movements velocity only.

The principal working condition of a valve section, keeping in mind that the complete valve could be composed by lots of sections (defined valve block), is that of define the outlet flow through the section to its actuator, maintain the pressure drop constant between the main spool metering area, define the LS pressure and provide the flow sharing operation condition when needed. It's easy understandable that a simple mathematical model for the valve cannot be able to recreate all of this functioning conditions.

For this reason the valve mathematical model has been developed not like a simple valve, but like a demi complex valve, the AMESim $^{\circledR}$ sketch is reported in fig.3, able to recreate the working functioning of the real valve. This has increased the simulation time if compare by an ideal valve model but has allowed to retain all the original working conditions, of the real valve section. This is the plus of this kind of mathematical model, able to recreate the interaction of all the valve sections.

\subsection{Governing Equations}

The governing equations are described by the interaction between a fluid-dynamic model (FDM) and a mechanical-geometrical model (MGM). The FDM calculates the pressures inside the chambers and the flow rate between adjacent chambers, while the MGM calculates the forces acting on the spool and determines its dynamics and the flow areas.

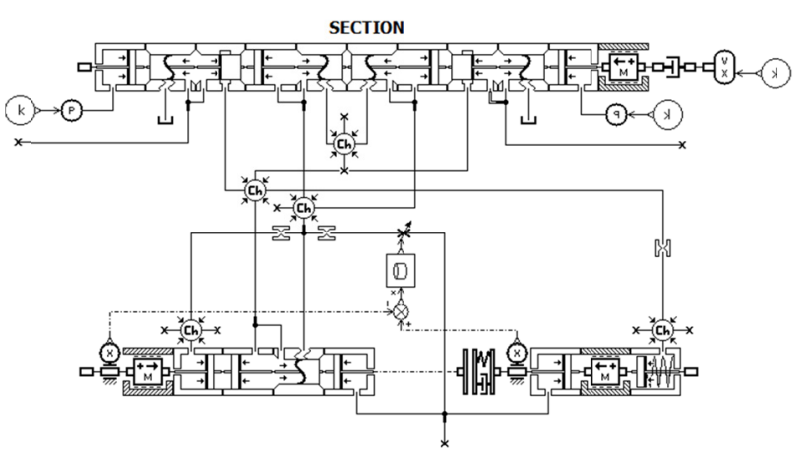

Figure 3: AMESim ${ }^{\circledR}$ Valve Section Mathematical Model

The FDM is based on a lumped parameter framework. The pressure inside each control volume is assumed uniform and time dependent, and is determined by the pressure-rise rate equation:

$$
\frac{d p_{i}}{d t}=\frac{\beta}{\rho_{i}} \frac{1}{V_{i}(x)}\left(\sum \dot{m}-\rho_{i} \frac{d V_{i}(x)}{d t}\right)
$$

The model assumes a constant value of fluid temperature. The fluid density is evaluated as a function of pressure as described in [9]. The summation term represents the net mass flow rate entering or leaving the volume. This is obtained by considering the contribution of all orifices connected with the considered volume. The mass exchange occurring through the orifices is calculated using the generalized Bernoulli's equation under quasi-steady conditions, Eq. (2):

$$
\dot{m}=\rho C_{d} A(x) \sqrt{\frac{2|\Delta p|}{\rho}}
$$

The user sets an appropriate saturated value for the coefficient of discharge of each connection, on the basis of experimental data or using values reported in literature, such as [10]; thereafter the instantaneous coefficient of discharge value is evaluated as a function of Reynolds number, to account for partially developed or fully turbulent conditions. The mechanical model calculates the instantaneous position and velocity of the spool using Newton's second law. 
The forces acting on the spool are: hydrostatic forces, spring force, friction forces, hydrodynamic forces. Static and dynamic friction forces are evaluated by use of the Karnopp friction model and considering the Stribeck effect; static and dynamic friction coefficients are assumed constant; in this simplified version of the model the hydrodynamic forces are neglected.

\section{Experimental Setup}

Figure 4 represents the ISO schematic of the test bench setup that has been used to verify the valve block functioning as a double sections. In table 1 are reported the features of the used sensors.

\begin{tabular}{|c|c|c|}
\hline Sensor & Type & Main features \\
\hline M & Prime mover & $\begin{array}{c}\mathrm{ABB}^{\circledR}, 4 \text {-quadrant electric motor, } \\
75 \mathrm{~kW}\end{array}$ \\
\hline$P$ & Pump & CASAPPA $^{\circledR} \mathrm{MVP} 60,84 \mathrm{~cm}^{3} / \mathrm{r}$ \\
\hline $\mathrm{P} 1-\mathrm{P} 8$ & Strain gage & $\begin{array}{c}\text { Trafag }^{\circledR}, \begin{array}{c}\text { Scale } 0.400 \text { bar, } 0.3 \% \text { FS } \\
\text { accuracy }\end{array}\end{array}$ \\
\hline $\mathrm{Q} 1-\mathrm{Q} 2$ & Flow meter & $\begin{array}{c}\mathrm{VSE}^{\mathbb{B}} \mathrm{VS} 1 \text {, Scale } 0.05 . .80 \mathrm{l} / \mathrm{min} \text {, } \\
0.3 \% \text { measured value accuracy }\end{array}$ \\
\hline $\mathrm{T}$ & Torque/speed meter & $\begin{array}{c}\mathrm{HBM}^{\circledR} \text { T, Scale: } 0 . .500 \mathrm{Nm}, 0.05 \\
\text { Accuracy Class }\end{array}$ \\
\hline$\Theta$ & Incremental encoder & $\begin{array}{c}\text { HEIDENHAIN }^{\circledR} \text { ERN120, }^{2} 600 \\
\mathrm{imp} . / \mathrm{r}, 4000 \mathrm{r} \text { min Limit velocity, } \\
1 / 20 \text { period accuracy }\end{array}$ \\
\hline LVDT & $\begin{array}{c}\text { Linear variable } \\
\text { differential transducer }\end{array}$ & Magnet Schuz AVAX 015 \\
\hline
\end{tabular}

Table 1: Features of sensors and main elements of the apparatus used in the present research
The tests were carried out using the valve block, composed by two valve sections coupled with the variable displacement pump.

The pump has been instrumented by an angular sensor directly connected with the swash plate.

Figure 5 illustrates the cross section of the valve along with the pressure mapping points and the mounting positions of the two LVDT's connected to the main spool and the pressure compensator.

Figure 6 show the test bench picture before starting the experimental test.

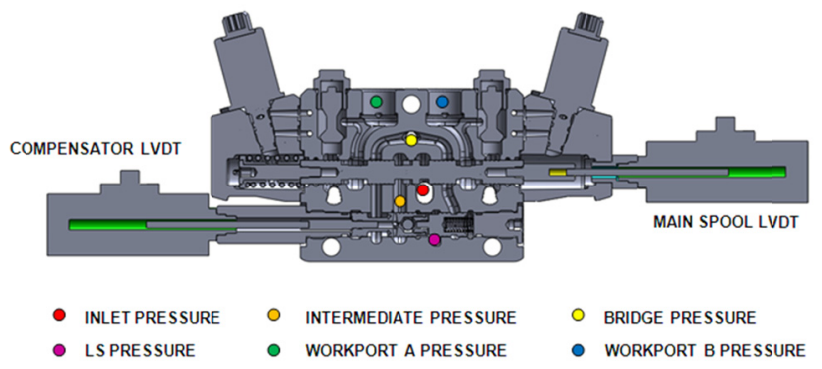

Figure 5: Valve with LVDT mounted and Pressure Mapping Points

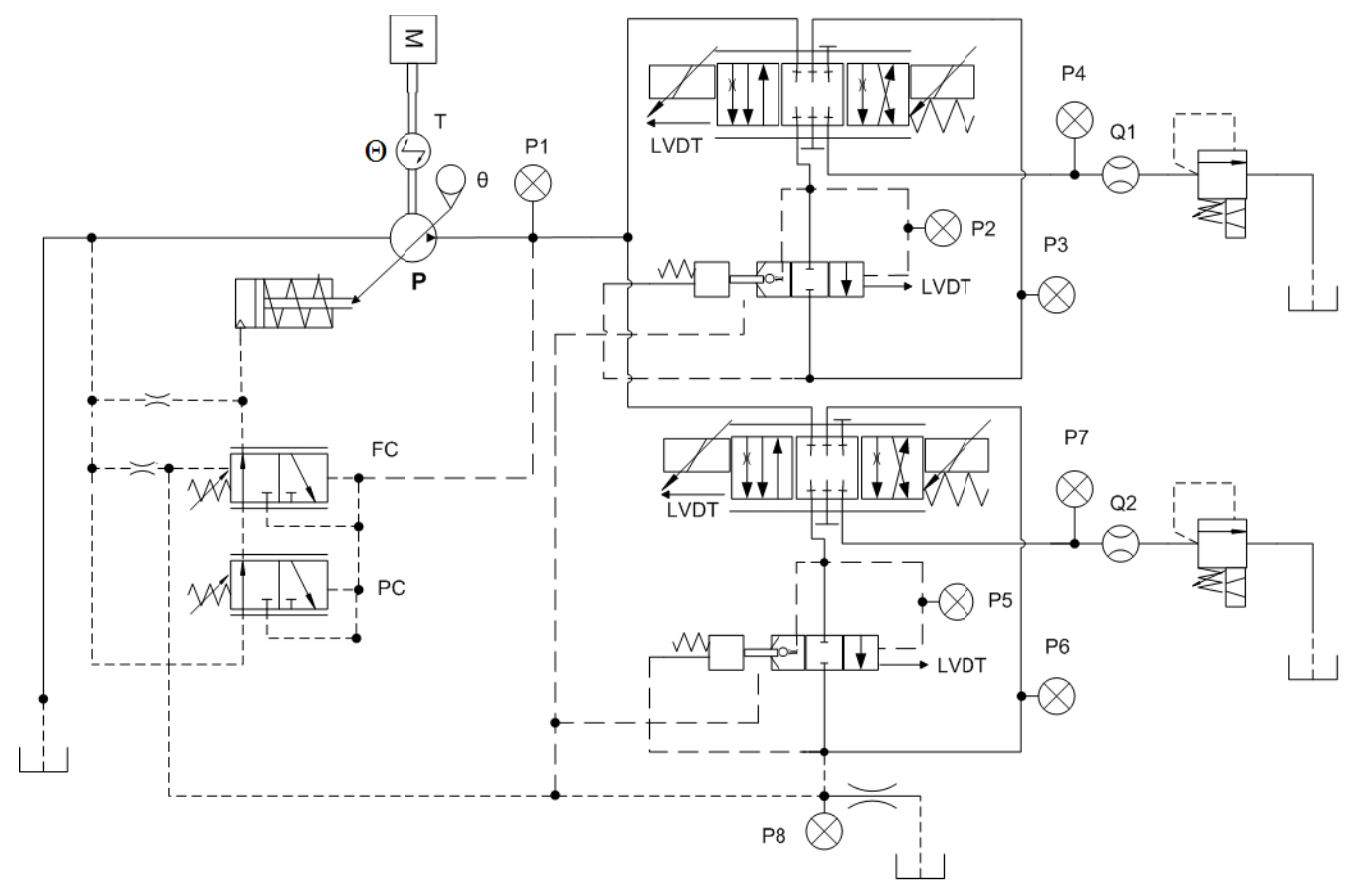

Figure 4: Test setup for Load Sensing Flow Sharing Valve Block 


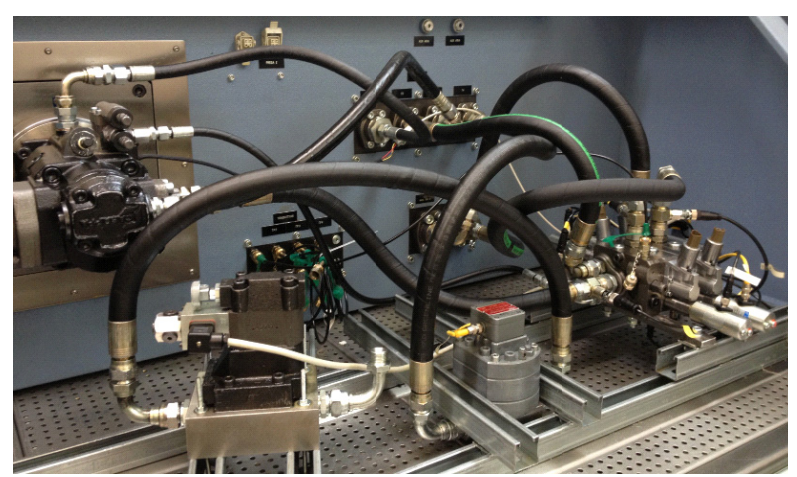

Figure 6: Test Bench Layout

\subsection{Experimental Setting condition}

As mentioned before, two different type of tests were carried out:

- Double pressure compensation, without flow saturation;

- Double pressure compensation, with flow saturation.

The first operating condition has been performed in standard condition, i.e. without flow saturation, defined as double pressure compensation, where the section 1 has a constant load and the section 2 has a variable load. The two loads pressure are display in fig.7.

The pump speed has been set at $1500 \mathrm{rpm}$ and the main spools opening position has been reported in fig. 8 . The pump margin has been set at 20 bar and the oil temperature at $50^{\circ} \mathrm{C}$.

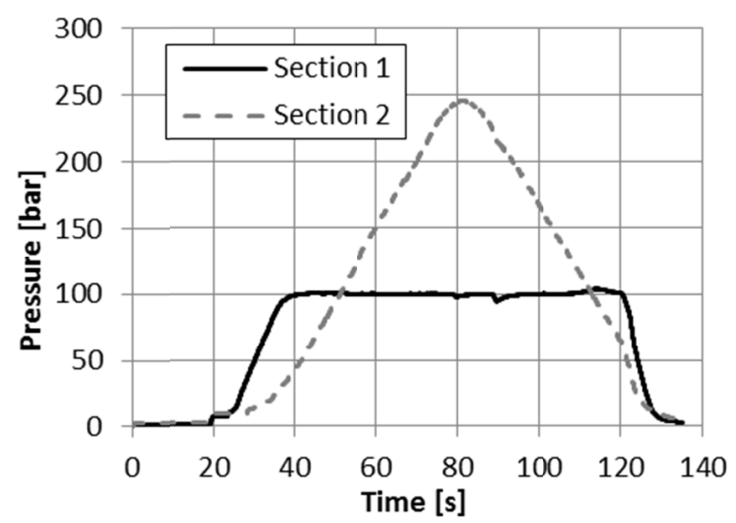

Figure 7: Sections Imposed Loads

The second operation condition has been performed in flow saturation, i.e. the required flow rate by the circuit is higher than the pump's outlet flow. The two sections load are represented in fig.9, the pump speed has been set at $1000 \mathrm{rpm}$ and the opening position law for the two main spools are depicted in fig.10. The pump margin has been set at 15 bar and the oil temperature maintained constant at $50{ }^{\circ} \mathrm{C}$.

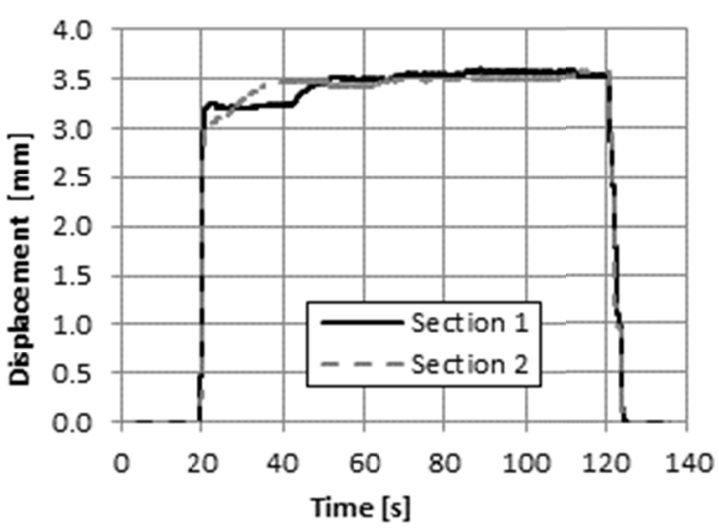

Figure 8: Main Spools Displacement

The transient pressure peaks, visible in fig. 9, are due to the test bench pressure proportional relief valve feedback control system setting. The transient does not introduce problem, rather if the mathematical model is able recreate this actual condition, will be very useful to prove the model accuracy.

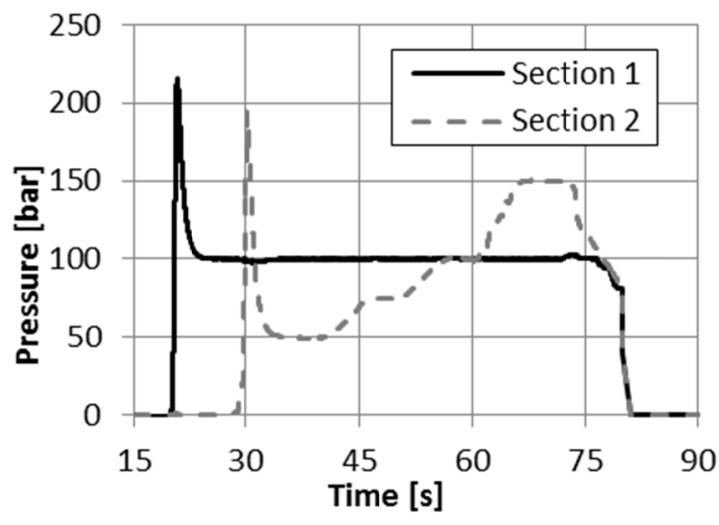

Figure 9: Sections Imposed Load

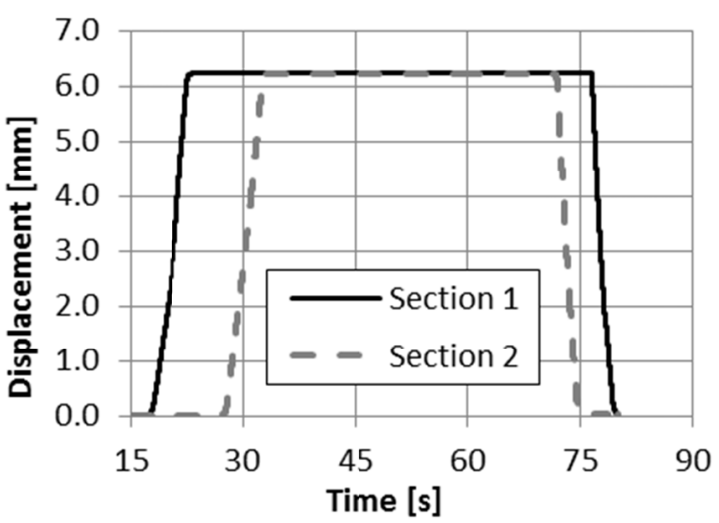

Figure 10: Main Spools Displacement 


\section{Comparison between experimental and simulation result}

Figure 11 depicts the AMEsim ${ }^{\circledR}$ sketch of the system comprising of the pump and valve used to recreate the layout mounted on the test bench, as shown in fig.4.

4.1 Double pressure compensation, no flow saturation

In this paragraph are compared the numerical and experimental result obtained during the first type of test.

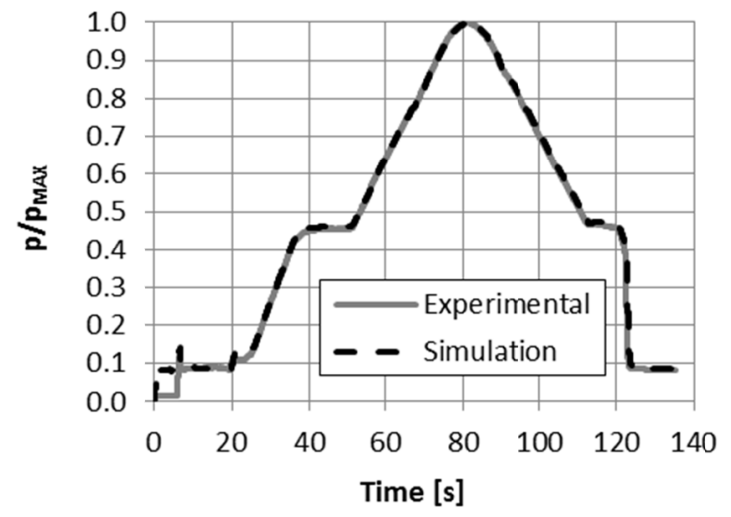

Figure 12: Inlet Pressure

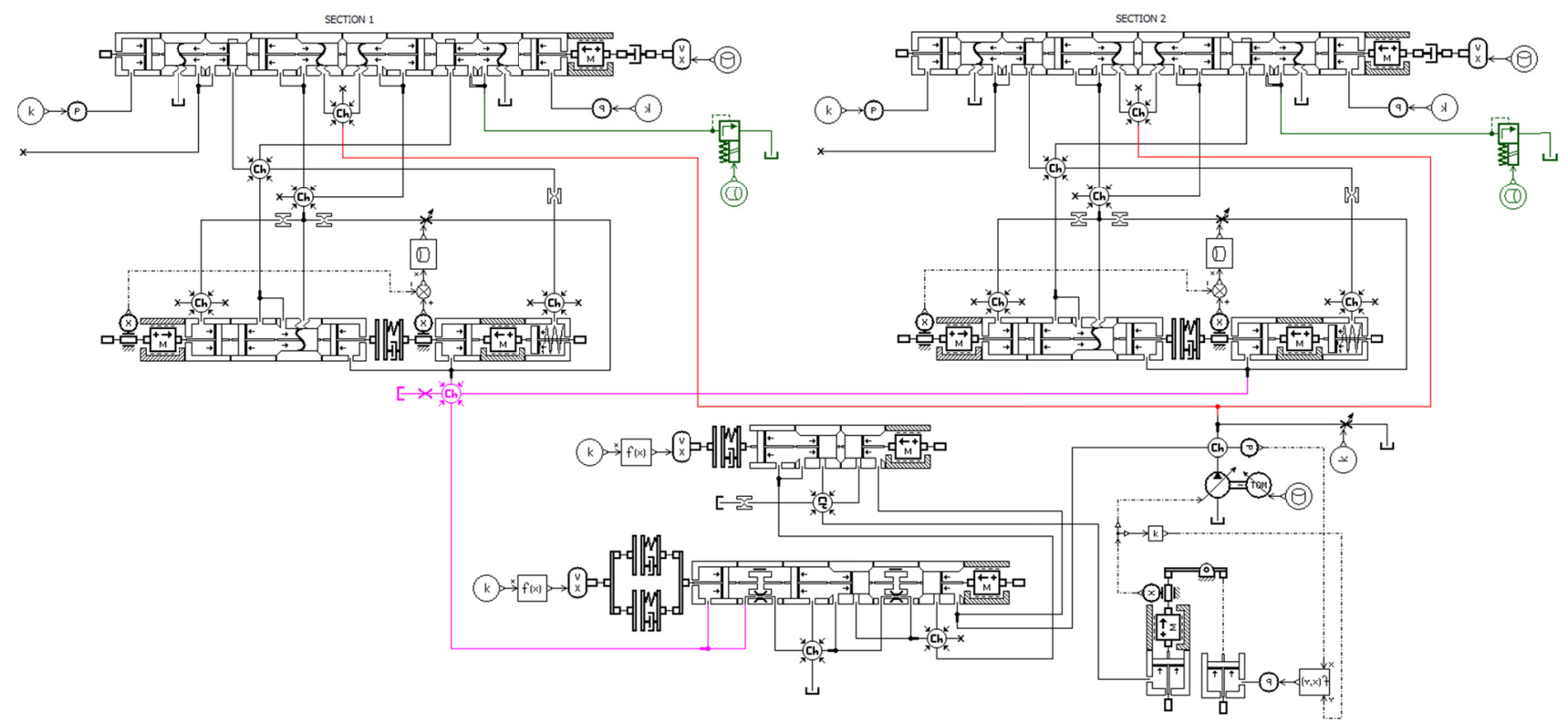

Figure 11: Test setup for Load Sensing Flow Sharing Valve Block

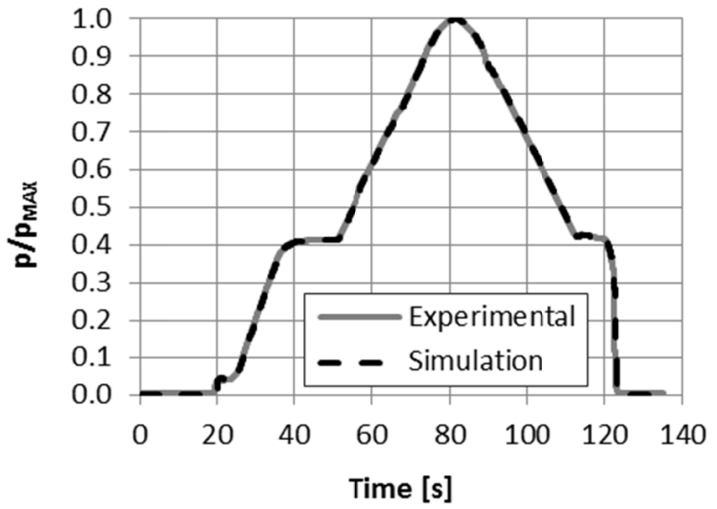

Figure 13: Load Sensing Pressure

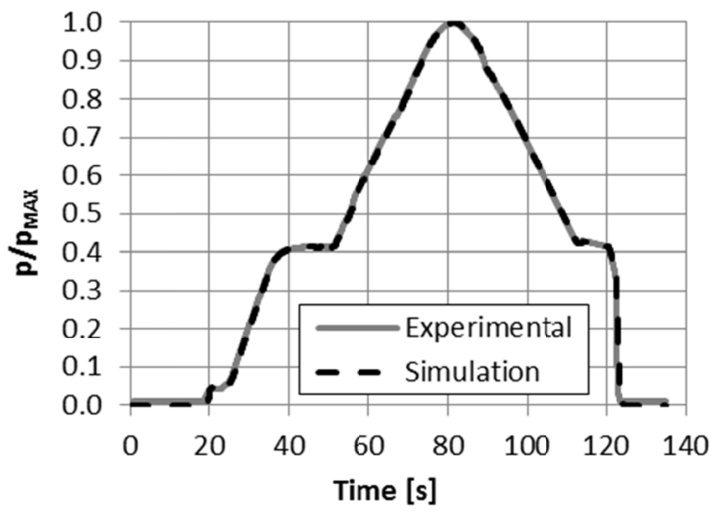

Figure 14: Intermediate Pressure Section 1 


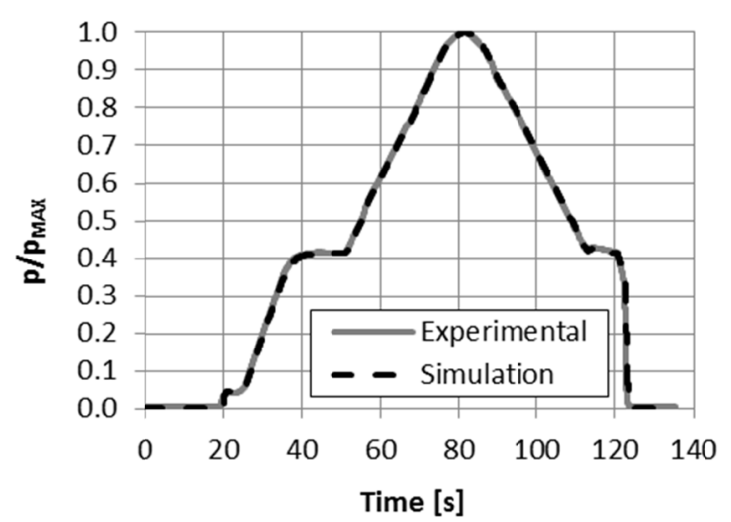

Figure 15: Intermediate Pressure Section 2

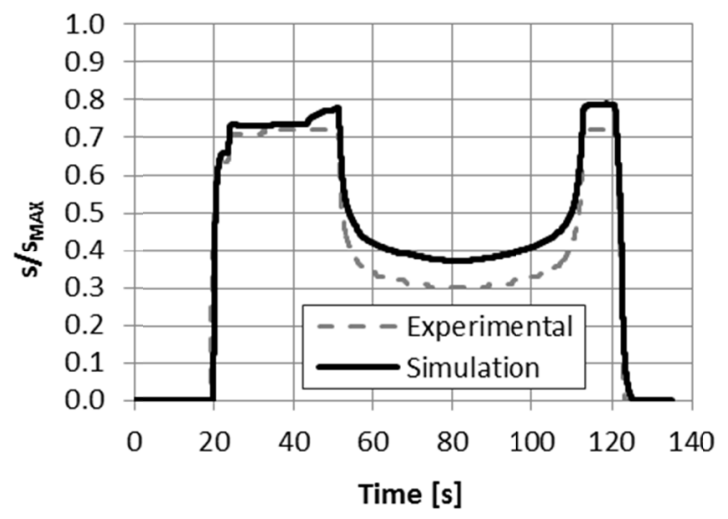

Figure 16: Compensator Displacement Section 1

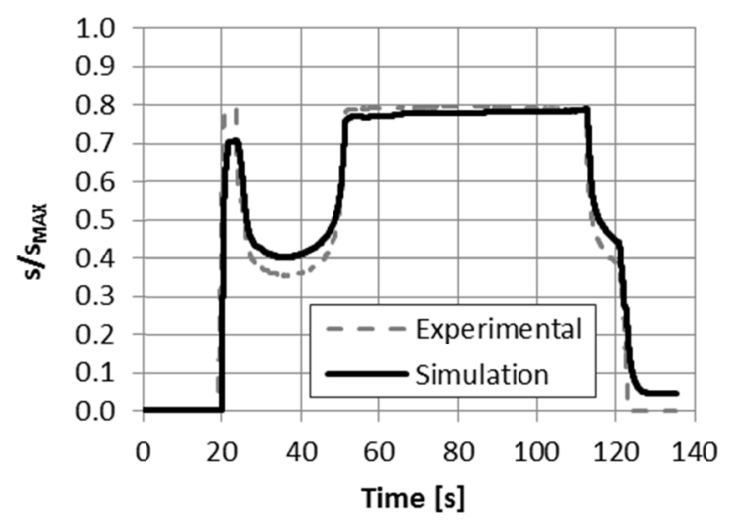

Figure 17: Compensator Displacement Section 2

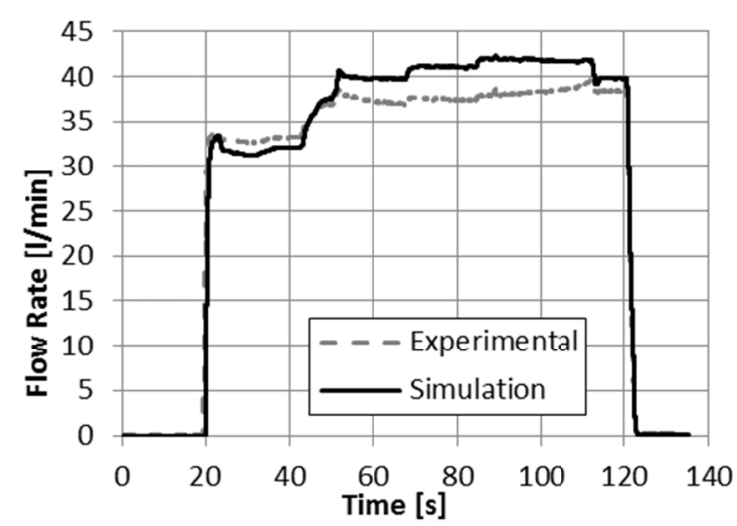

Figure 18: Outlet Flow Rate Section 1

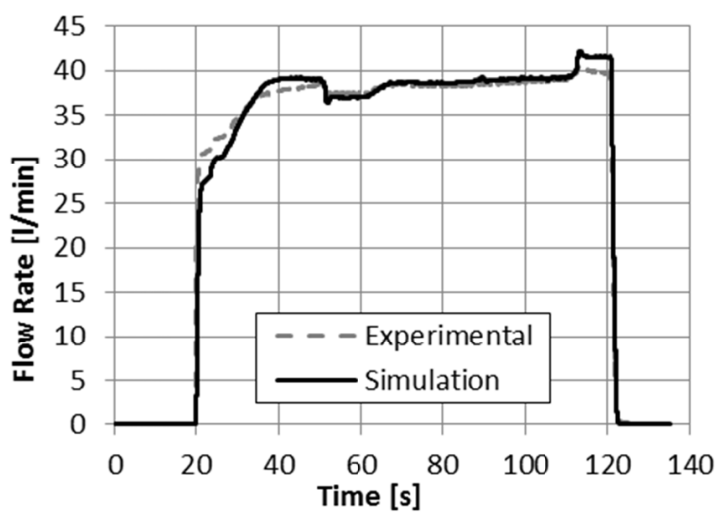

Figure 19: Outlet Flow Rate Section 2

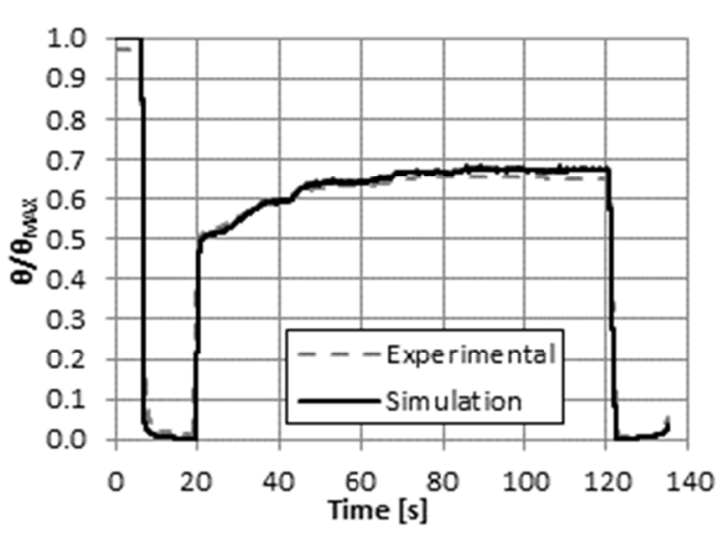

Figure 20: Pump Swash Plate Position 
Figures 12, 13 show the comparison of the inlet and the load sensing pressure. This two pressures are common for all the valve sections.

Figure 14, 15 refer to section 1 and 2 intermediate pressures (see fig. 5). The comparison between section 1 and 2 pressure compensators displacement are showed in figures 16 and 17.

Figures 18, 19 depict the comparison between the experimental and simulation outlet flow rates from section 1 and the section 2 .

As can be seen the model has the capability to recreate all the pressures inside the chambers with errors under $2 \%$ if compare with the experimental data; further the mathematical model is able to recreate the outlet flow rates with a maximum error among $10 \%$, acceptable for a simplified model.

It's possible to observe that the model has also a good capability to calculate the actual compensators position.

Figure 20 reports the pump swash plate position, where the simulation data match the experimental position accurately.

\subsection{Double pressure compensation, with flow saturation}

In this paragraph are compared the numerical and experimental result obtained during the second type of test. Figures $21-24$ show the pressure inside the chambers in the valve block: the inlet and LS pressure, common for the valve block and the intermediate pressures. Figures 26, 27 show the sections outlet flow rates comparison. When the flow saturation occur, between 30 s and $70 \mathrm{~s}$, the outlet flow rate from section 1 decreases until the section 2 main spool remains open.

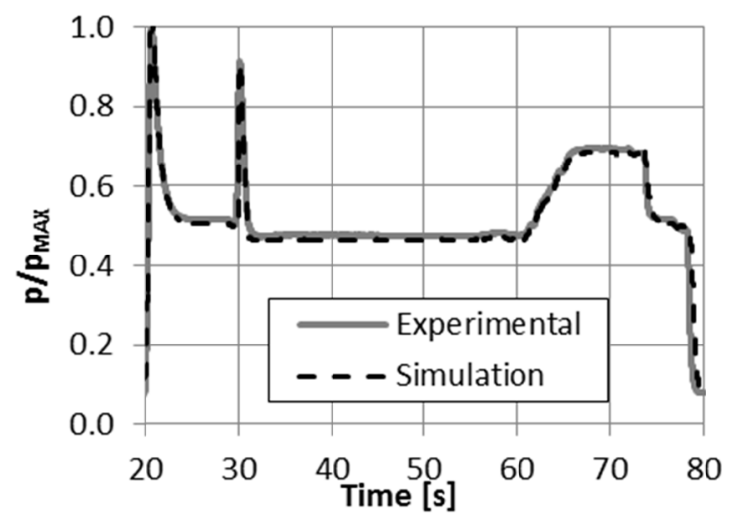

Figure 21: Inlet Pressure

Figure 25 depicts the displacement of the section 2, unfortunately is not possible compare it with the section 1 pressure compensator position due to the LVDT absence when this test has been carried out. As already seen in the double pressure compensation test without flow saturation condition, the model of the valve section has the capability to perform good result for the two working conditions. The outlet flow rates and the pressure compensator position are recreated in an acceptable way by the model and the pressures match the experimental one satisfactorily.

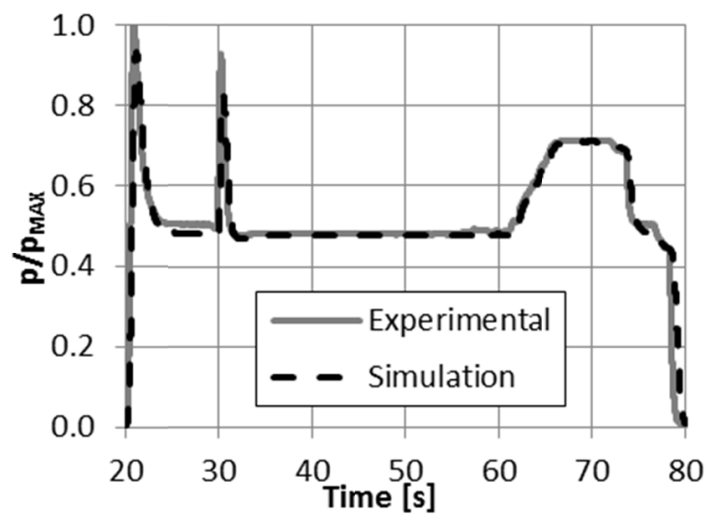

Figure 22: Load Sensing Pressure

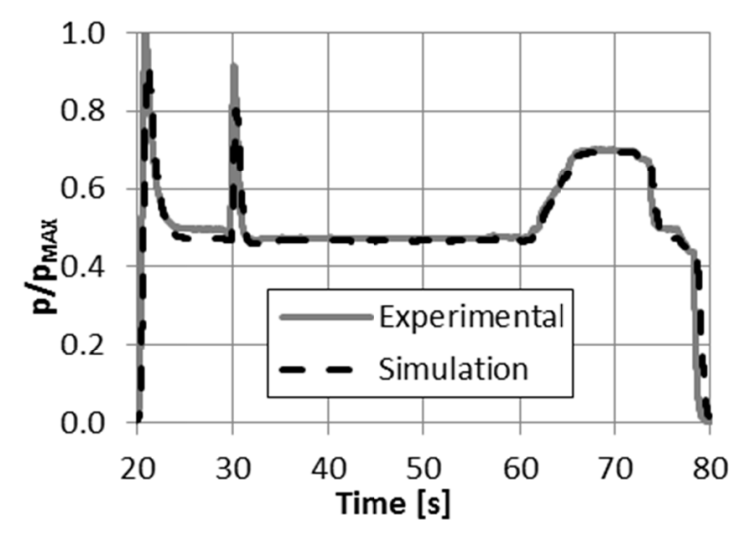

Figure 23: Intermediate Pressure Section 1

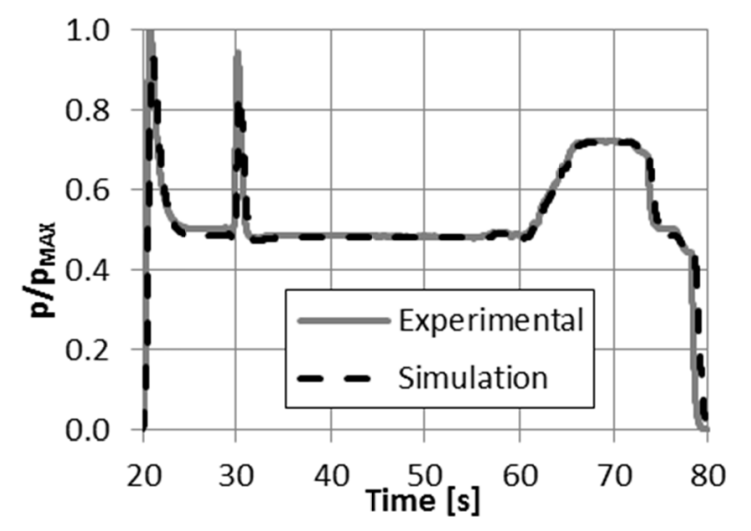

Figure 24: Intermediate Pressure Section 2 


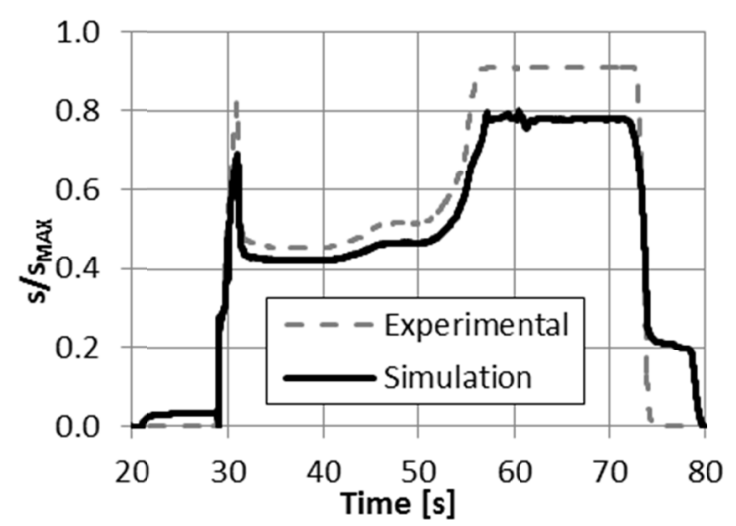

Figure 25: Compensator Displacement Section 2

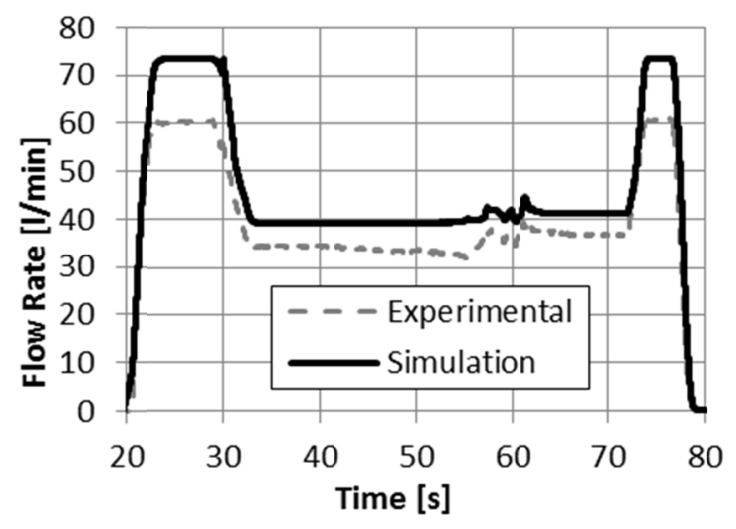

Figure 26: Outlet Flow rate Section 1

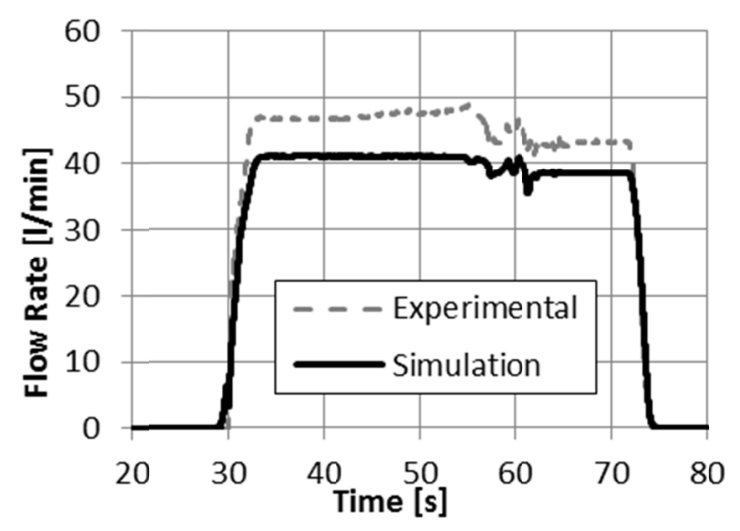

Figure 27: Outlet Flow rate Section 2

\section{Excavator Model and cycle simulation}

The excavator under study is a middle size one and is depicted in fig 28. Its operating weight is $9500 \mathrm{~kg}$ and the engine power is $46.5 \mathrm{~kW}$ at $2200 \mathrm{rpm}$.

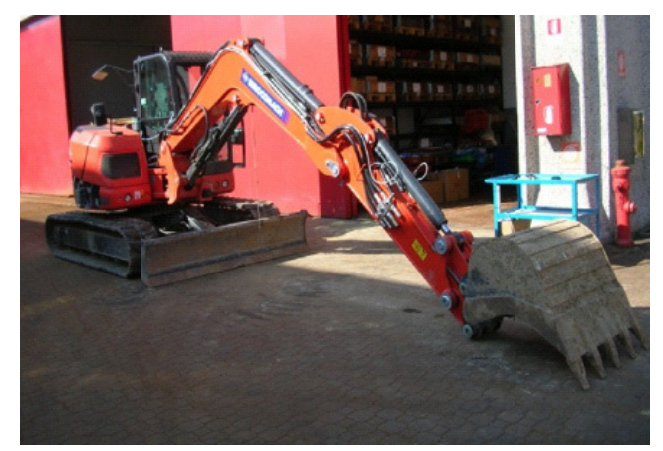

Figure 28: Photograph of the excavator

Based on the analysis of results presented in the previous section, it is evident that the pump and valve models are capable of reproducing actual conditions. Thus to widen the model capabilities the kinematics has been included as illustrated in fig 34 .

The complete system was subjected to a duty cycle as described in fig 29. The pump speed has been set at $1500 \mathrm{rpm}$. Figure 30 shows the simulated system and LS pressures. The sections inlet flow rates are depicted in fig 31. Figure 32 reports the section compensators position during the cycle and it's possible observe the model capability to recreate the compensating mode. Figure 33 depicts the pump swash plate position. The figures in this section provides to the system developers an insight into the internal functioning of the pump and the valve. These information are needful for studying new control strategies or proposing improvements in the design of these components.

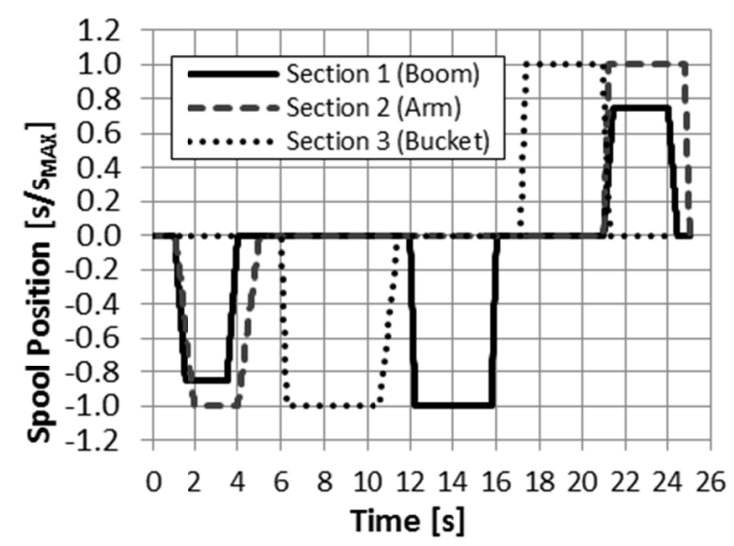

Figure 29: Valve section spools position 


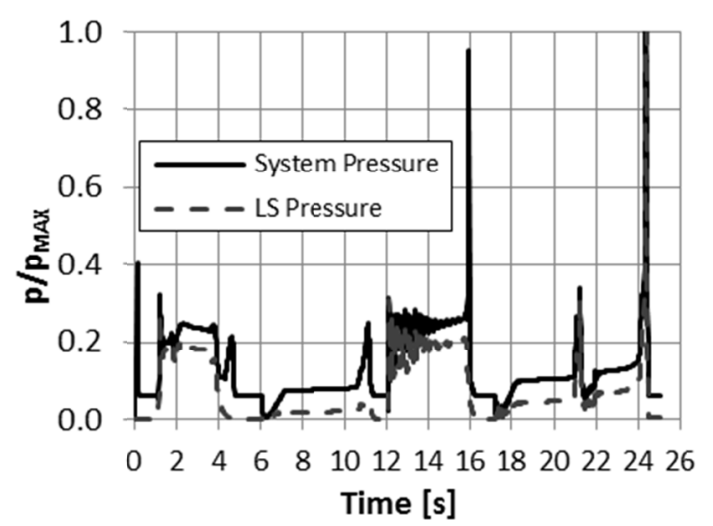

Figure 30: System and Load Sensing pressure

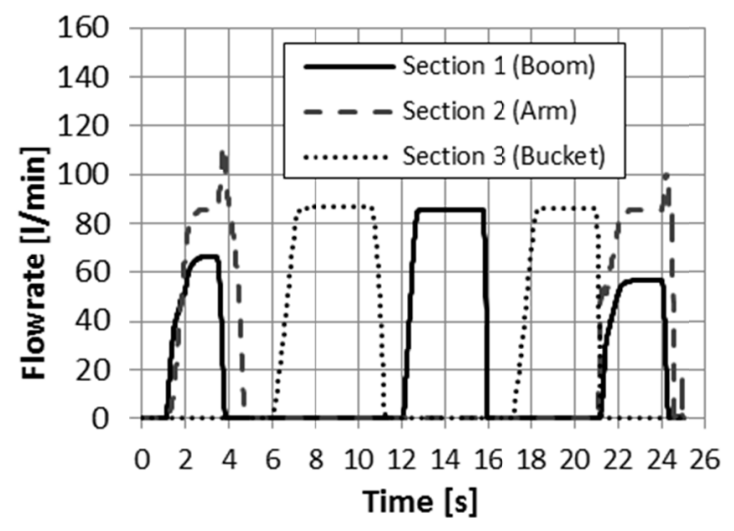

Figure 31: Sections inlet flow rate

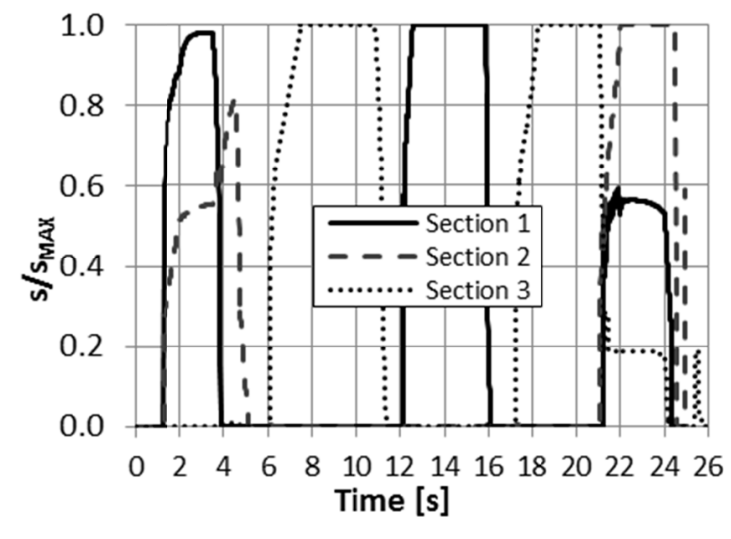

Figure 32: Sections compensator displacement

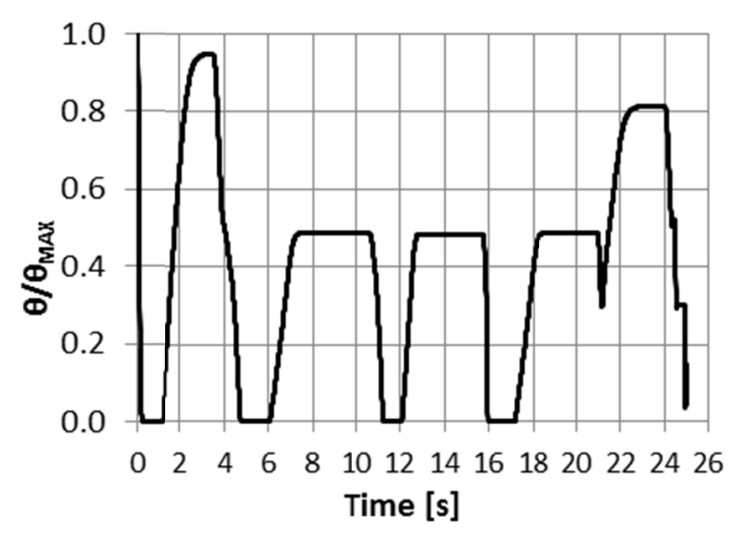

Figure 33: Pump swash plate position

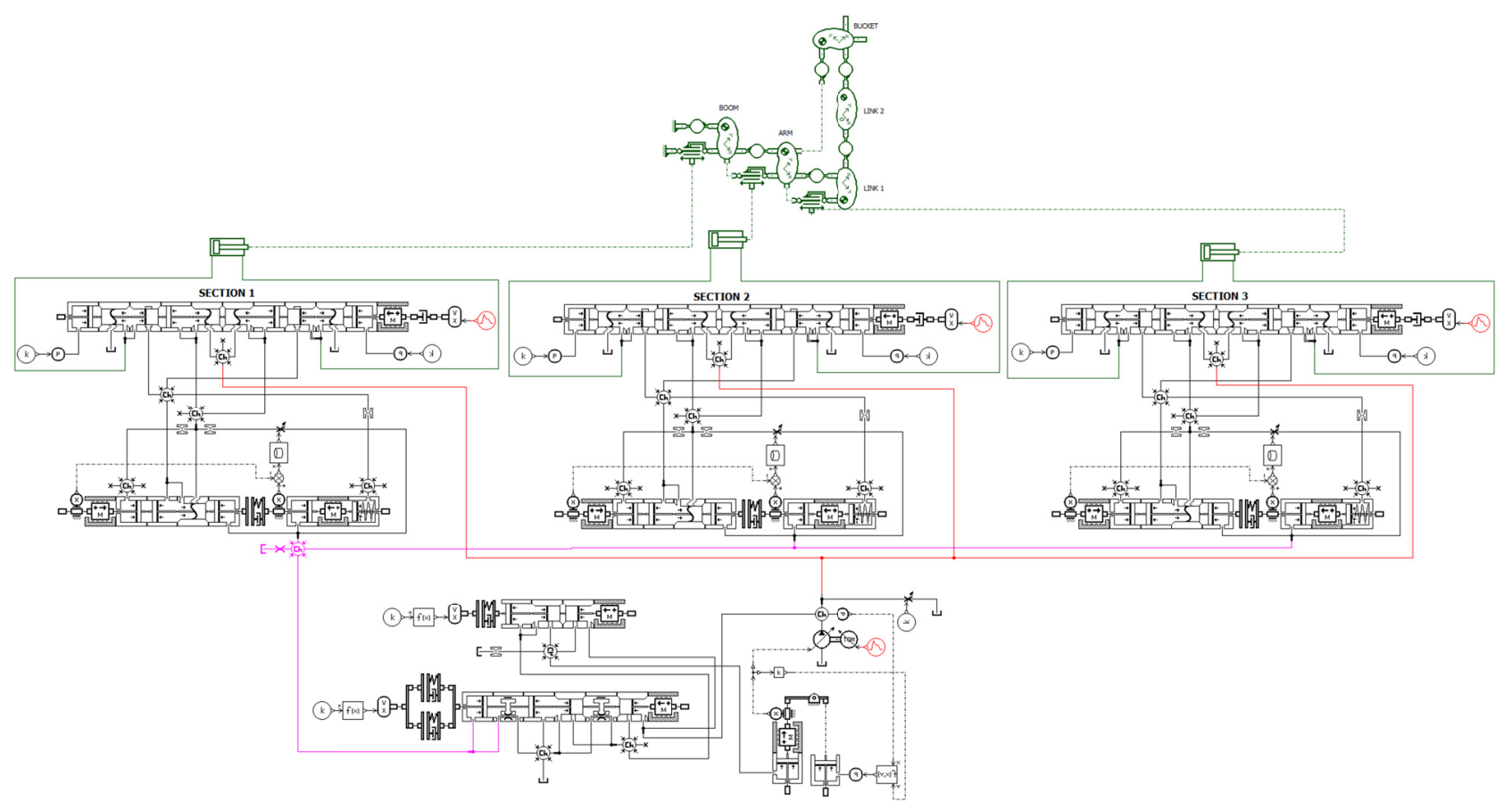

Figure 34: AMESim ${ }^{\circledR}$ sketch of the front excavator tool and hydraulic circuit. 


\section{Conclusion}

This paper has presented the analysis of an excavator system. A nonlinear mathematical model of an excavator has been developed using the AMESim ${ }^{\circledR}$ modeling environment to replicate real operating conditions. The model is described by hydraulic model comprising of a load sensing pump, a flow sharing valve model and a $2 \mathrm{D}$ kinematic model to simulate the excavator front excavation tool. This approach has enabled the study of the dynamic behavior and interaction of the pump and valve with a completely developed kinematic model of the excavator. The detailed hydraulic model described regard a load sensing flow sharing valve block, composed by two valve sections model working at the same time. The mathematical model of the valve has been validated against experimental results in different conditions: standard operating without flow saturation and flow sharing condition, i.e. with flow saturation. The pump and valve models and their verification, as represented in this paper, offer a great deal of confidence in the individual models capabilities of recreating the functioning of an excavator. The last section of the paper provides an overall view of the hydraulic model capability coupled with the kinematics of the system, with the simulation of an arm-bucket movement. The results presented show the paramount of advantages that this model possess in aiding a pump and valve designers in analyzing/assessing the behavior of the components as a part of a complex system.

The mathematical model of the excavator could be useful in future study of both new control system and new energy saving solutions.

\section{Acknowledgments}

The authors would like to acknowledge the active support of this research by Casappa S.p.A., and Walvoil S.p.A (ITALY).

\section{Nomenclature}

\begin{tabular}{llc}
\hline$A$ & flow area & {$\left[\mathrm{m}^{2}\right]$} \\
$C_{d}$ & discharge coefficient & - \\
$i$ & volume index & - \\
$\dot{m}$ & mass flow rate & {$[\mathrm{kg} / \mathrm{s}]$} \\
$p$ & pressure & {$[\mathrm{bar}]$} \\
$V$ & volume & {$\left[\mathrm{m}^{3}\right]$} \\
$t$ & time & {$[\mathrm{s}]$} \\
& & \\
& Greek Letters & {$[\mathrm{Pa}]$} \\
\hline$\beta$ & bulk modulus &
\end{tabular}

\begin{tabular}{lll}
\hline$\rho$ & density & {$\left[\mathrm{kg} / \mathrm{m}^{3}\right]$} \\
\hline & Acronyms & \\
\hline FC & Flow compensator & \\
PC & Pressure compensator & \\
PS & System Pressure & \\
PLS & Load Sensed Pressure & \\
\hline
\end{tabular}

\section{References}

[1] JCMAS H 020 - Earth Moving machinery - Test methods for energy consumption - Hydraulic excavators, 2010.

[2] J Ivantysyn , M Ivantysynova. Hydrostatic Pumps and Motors, Tech Books International, New Delhi,2003, India. ISBN 81-88305-08-

[3] Blakburn J. F., Reethof G. \& Shearer J. L. (1966) "Fluid Power Control". USA: MIT Press, 1966. ISBN 0262520044

[4] P. Casoli, A. Anthony (2013) "Gray box modeling of an excavator's variable displacement hydraulic pump for fast simulation of excavation cycles" Control Engineering Practice 21 (2013) pp.483494. Elsevier Ltd. http:/dx.doi.org/10.1016/j.conengprac.2012.11.011

[5] LMS Imagine - AMESim $^{\circledR}$ Reference manual 2011

[6] Shih-Tin Lin, Jiann-Nan Huang. (2002) .Stabilization of Baumgarte's Method Using the Runge-Kutta Approach. In ASME Journal of Mechanical Design, vol. 124, n.4, pp. 633-641. December 2002.

[7] Grzesikiewicz, W. (1998). Dynamics of a ground digging tool. XI scientific Conference Problems of Work Machines, konferencja Naukova Problem Maszyn Roboczych) Polska: Zakopane, 1998.

[8] P. Casoli, A. Anthony, L. Riccò (2012) "Modeling of an Excavator System - Load sensing flow sharing valve model" SAE 2012 Commercial Vehicle Engineering Congress, Rosemont, Illinois, USA, 13-14 September 2012. doi:10.4271/2012$01-2042 \mathrm{H}$

[9] E Merritt. Hydraulic Control Systems. John Wileys and Sons, Cincinnati, Ohio, 1967. ISBN 0-47159617-5.

[10] McCloy, D., Martin, H. M. (1973). "The control of Fluid Power", Longman, London, 1973. 